\title{
Nucleosome displacement in transcription
}

\author{
Jerry L. Workman ${ }^{1}$ \\ Stowers Institute for Medical Research, Kansas City, Missouri 64110, USA
}

Recent reports reinforce the notion that nucleosomes are highly dynamic in response to the process of transcription. Nucleosomes are displaced at promoters during gene activation in a process that involves histone modification, ATP-dependent nucleosome remodeling complexes, histone chaperones and perhaps histone variants. During transcription elongation nucleosomes are acetylated and transferred behind RNA polymerase II where they are required to suppress spurious transcription initiation within the body of the gene. It is becoming increasingly clear that the eukaryotic transcriptional machinery is adapted to exploit the presence of nucleosomes in very sophisticated ways.

\section{Nucleosome-free regions at gene promoters}

Removal of nucleosomes has been a long-standing hypothesis for how genes might become activated, but only recently have experiments begun to rigorously address this topic. For some time after the discovery of DNasehypersensitive sites (DHSs) in chromatin (for review, see Elgin 1981), it was anticipated that these nuclease sensitive regions would correspond to segments along the chromosome that are free of nucleosomes. With the common occurrence of DHSs at known transcriptional regulatory regions such as enhancers and promoters, mapping these exposed sites in genomic DNA became a powerful tool for identifying novel regulatory sites such as locus control regions (LCRs) and other functional genomic sequences (for review see, Gross and Garrard 1988). However, the question of whether these sites were actually histone free or simply did not look like nucleosomes to nucleases remained unresolved. The initial idea that DHSs must be nucleosome-free was attractive since the structure and stability of nucleosomes did not seem likely to accommodate the cobinding of transcription factors (Brown 1984; Kornberg and Lorch 1991). Early support for the notion that at least some of these regions are free of histones came from McGhee and Felsenfeld (McGhee et al. 1981), who examined the chicken adult $\beta$-globin DHS by restriction endonuclease

[Keywords: Histone; nucleosome; transcription; transcription elongation; transcription initiation]

${ }^{1}$ Correspondence.

E-MAIL jlw@stowers-institute.org; FAX (816) 926-4692

Article is online at http://www.genesdev.org/cgi/doi/10.1101/gad.1435706. digestion. They showed the release of a 115-base-pair (bp) fragment from the DHS, of which one-third migrated on gels like naked DNA. In contrast, studies of an inducible DHS at the MMTV promoter suggested that it was still occupied by core histones following induction (Bresnick et al. 1992; Truss et al. 1995), thereby demonstrating the co-occupancy of histones and transcription factors. Moreover, a DHS could be reconstituted by the binding of transcription factors to the HIV-1 enhancer within a nucleosome array without the loss of histones (Steger and Workman 1997; Angelov et al. 2000). Thus, while DHSs do not appear to contain canonical nucleosomes as defined by nuclease digestion, an altered nucleosome or alternative histone DNA complex may still exist at these sites in some instances. Nevertheless, remembering the caveat that DHSs might still be bound by histones, we will refer to these sites as nucleosome-free for the purposes of this review.

\section{Nucleosome distribution in Saccharomyces cerevisiae}

Studies in Saccharomyces have provided striking information regarding the prevalence and distribution of nucleosome-free regions. Using conventional indirect end labeling to map nucleosome positions across 45,000 bp of chromosome III in both mating types, Ercan and Simpson (2004) observed highly positioned nucleosome arrays over numerous ORFs, as well as over the promoters of actively repressed genes. By contrast, nucleosomefree DHSs were observed in the promoter region of nearly every other gene examined. The presence of these DHSs did not correlate with transcription rates from the corresponding promoters, suggesting that DHSs reflect transcriptional competence more than transcriptional activity.

Chromatin immunoprecipitation experiments using antibodies directed against core histones or to an epitope tag on the core histones have provided further insights into the location and occupancy level of promoters with nucleosomes in Saccharomyces (Ercan et al. 2004). For example, the Rando laboratory (Yuan et al. 2005) applied anti-histone chromatin immunoprecipitates to highresolution microarrays that covered $482 \mathrm{~kb}$ of the Saccharomyces genome with 50-bp oligonucleotides, tiled every $20 \mathrm{bp}$. This study mapped 2278 nucleosomes and found that most, but not all, are well positioned. Strikingly, most polymerase II transcribed genes contain a 
nucleosome-free gap of $\sim 200$ bp over the promoter, flanked by two well-positioned nucleosomes. The nucleosome-free regions include known DHSs and occupied transcription factor-binding sites. The nucleosomes flanking the nucleosome-free region appear to be deacetylated and enriched in the histone variant H2A.Z (Liu et al. 2005; Raisner et al. 2005) Moreover, H2A.Z plays a role in the activation of gene transcription, yet appears to be concentrated on the promoters of genes that are silent (Santisteban et al. 2000; Guillemette et al. 2005; Li et al. 2005; Raisner et al. 2005; Zhang et al. 2005). Thus, these data suggest that silent but inducible yeast genes are poised with a nucleosome-free DHS at the promoter flanked by two H2A.Z-containing nucleosomes (Fig. 1A).

A somewhat different picture emerges from analysis of DNA sequences in anti-histone chromatin immunoprecipitates using lower-resolution yeast genome-wide microarrays. These studies, with microarrays that included amplified intergenic regions or the entire yeast genome at $1-\mathrm{kb}$ resolution, revealed an apparent depletion of nucleosomes at active regulatory elements (Bernstein et al. 2004; Lee et al. 2004). They demonstrated an inverse correlation between nucleosome occupancy at upstream regulatory elements, as measured by the presence of histones, and rates of transcription of the corresponding ORF (Bernstein et al. 2004; Lee et al. 2004). Interestingly, alteration of transcription programs by treatments such as a change in carbon source resulted in newly repressed genes gaining nucleosomes, while newly activated genes lost nucleosomes (Lee et al. 2004). As discussed in more detail below, these studies also showed that the most highly transcribed genes are often partially depleted of nucleosomes in coding regions (Lee et al. 2004).

The above observations appear, at first glance, to be inconsistent. Nuclease mapping studies (Ercan and Simpson 2004) and high-resolution chromatin immunoprecipitation studies (Yuan et al. 2005) both indicate that most promoters have hypersensitive sites regardless of activity, whereas genome-wide studies suggest that the nucleosome density of promoters is inversely proportional to transcription activity (Bernstein et al. 2004; Lee et al. 2004). These apparent differences might be reconciled, however, if additional nucleosomes are lost upon gene induction (see Fig. 1B). Indeed, there are many examples of such a phenomenon in the literature. Perhaps the yeast PHO5 gene, studied extensively by Horz and colleagues, is the best-characterized example of an inducible promoter in which nucleosomes are lost upon induction (for review, see Svaren and Horz 1997). Strikingly, this group observed that histones at the promoter were acetylated by GCN5 (the catalytic subunit of SAGA and other acetyltransferase complexes) and subsequently lost contact with the promoter DNA (Reinke and Horz 2003). In a related paper, Boeger et al. (2003) reported that these nucleosomes were actually unfolded such that the histone octamer was no longer wrapped with DNA. Notably, these nucleosomes were still lost when the PHO5 promoter was placed in small chromosome circles, suggesting that they were lost in trans
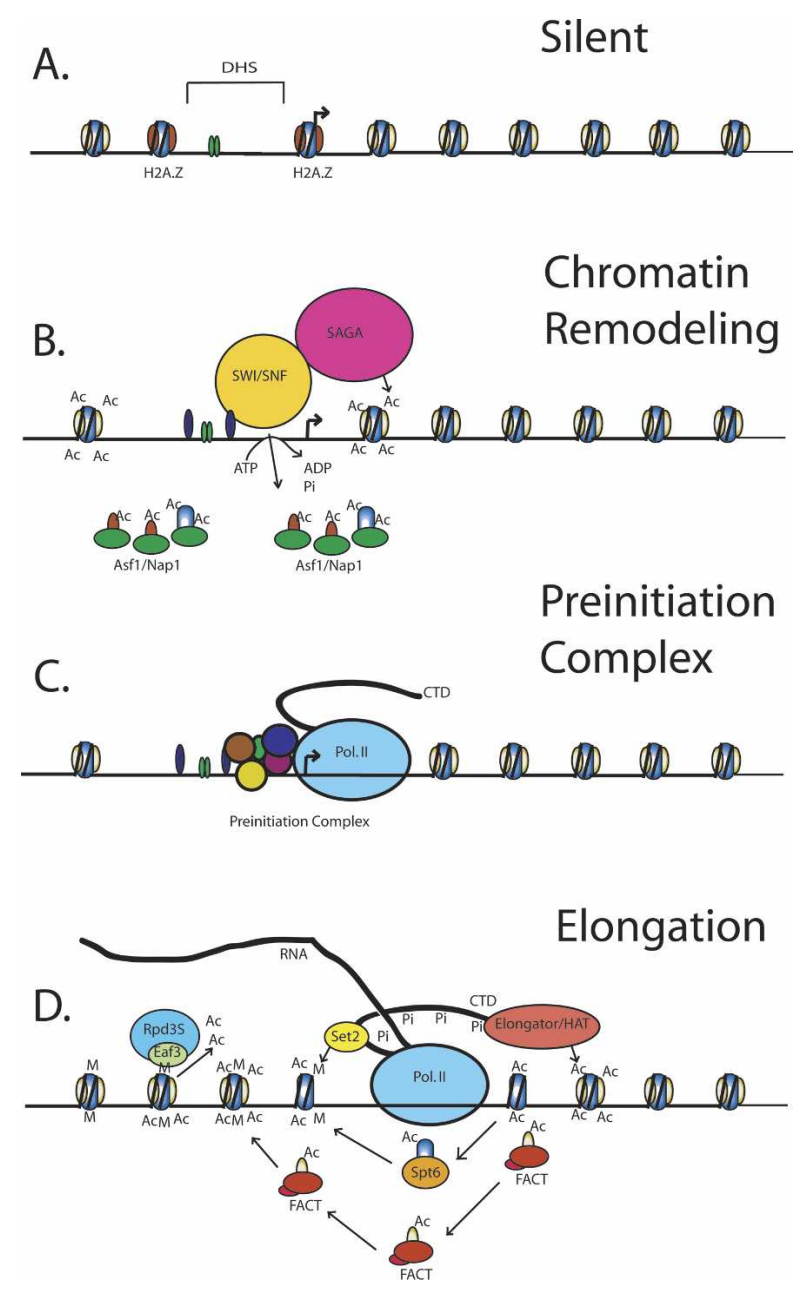

Figure 1. Model of nucleosome dynamics during transcription of a yeast gene. (A) Silent but inducible yeast genes contain a nucleosome-free gap at the upstream activation sequence (UAS) that may be occupied by one or more sequence-specific binding factors (green ovals) flanked by two H2A.Z-containing nucleosomes. (B) Upon activation, additional DNA-binding activators (blue ovals) are bound to the UAS that then recruit SAGA and SWI/SNF complexes. SAGA acetylates promoter nucleosomes, which facilitates the displacement of the H2A.Z-containing nucleosomes and perhaps additional nucleosomes by SWI/SNF. The histones are transferred onto the Asfl and Napl histone chaperones. $(C)$ The resulting nucleosome-free region is then available for the formation of a preinitiation transcription complex including RNA polymerase II. (D) During transcription, elongation acetyltransferase complexes associated with the elongating polymerase acetylate nucleosomes in front of the polymerase. This facilitates their partial or complete disassembly, transferring the histones onto the Spt6 and FACT histone chaperones. Spt6 and FACT reassemble nucleosomes behind the polymerase, and histone $\mathrm{H} 3$ is methylated by the polymerase-bound Set2 methyltransferase. The Eaf3 subunit of the Rpd3S histone deacetylase complex recognizes the methylated histone $\mathrm{H} 3$ and deacetylates those nucleosomes to restore their previous stability. The reassembled nucleosomes behind polymerase may also contain new histones from the soluble cellular pool.

rather than by sliding along the DNA in cis (Boeger et al. 2003, 2004; Korber et al. 2004, 2006). 
Studies of H2A.Z localization genome-wide in yeast also support the notion that additional promoter nucleosomes are lost upon gene induction. While H2A.Z-containing nucleosomes flank the nucleosome-free regions of silent promoters, their occupancy is reduced on promoters that are active. Moreover, altering transcriptional programs (e.g., by changing growth conditions) leads to a reduction of $\mathrm{H} 2 \mathrm{~A} . \mathrm{Z}$ on promoters that are activated (Guillemette et al. 2005; Li et al. 2005; Raisner et al. 2005; Zhang et al. 2005). These results are consistent with the displacement of H2A.Z-containing promoter nucleosomes upon gene activation (Fig. 1B). Recent reports, however, suggest that not all H2A.Z nucleosomes are lost from promoters upon activation. While H2A.Z overall is enriched at silent promoters, a version of the protein that is acetylated on Lys 14 is enriched on active promoters (Millar et al. 2006). Moreover, acetylation of H2A.Z is carried out by the NuA4 complex and perhaps also SAGA (Babiarz et al. 2006; Keogh et al. 2006; Millar et al. 2006). NuA4 is an acetyltransferase complex that can be recruited to promoters by transcription factors in the same manner as the SAGA complex (Utley et al. 1998; Brown et al. 2001). Thus, while a picture emerges of H2A.Z nucleosomes being acetylated and then displaced from promoters during gene activation (Fig. 1B), this acetylation may involve multiple acetyltransferase complexes and the displacement of these nucleosomes may not be complete.

Displacement of specific histones and entire nucleosomes may be widespread at promoters in the response of transcription to inducers. For example, Shannon and colleagues (Chen et al. 2005) found depletion of histones $\mathrm{H} 3$ and $\mathrm{H} 4$ from the interleukin-2 gene during T-cell activation. In addition, progesterone activation of the mouse mammary tumor virus promoter reportedly leads to loss of $\mathrm{H} 2 \mathrm{~A}$ and $\mathrm{H} 2 \mathrm{~B}$ from the nucleosome bound by the progesterone receptor (Vicent et al. 2004). Lastly, histones are lost over entire heat-shock genes in Saccharomyces upon heat shock (Zhao et al. 2005).

\section{How are nucleosome-free regions generated?}

Because of the numerous histone DNA contacts within a nucleosome, they are one of the most stable proteinDNA complexes in vitro at physiological salt concentrations. This raises the question of how nucleosomes might be moved so nucleosome-free gaps might be generated. Early models proposed that transcription factors compete with nucleosomes during DNA replication, forming stable complexes that exclude nucleosomes from promoters of active genes during chromatin assembly (Brown 1984). Moreover, both in vivo and in vitro studies suggest that such a mechanism may function at certain promoters (Barton and Crowe 2001). On the other hand, pre-existing nucleosomes can be displaced upon gene induction, an alternative mechanism for which there are clear examples (for review, see Adams and Workman 1993). Biochemical studies have illustrated how transcription factors might contribute to the removal of nucleosomes from a segment of DNA (for re- view, see Steger and Workman 1996). These studies have generally illustrated how transcription factor binding to nucleosomal DNA destabilizes nucleosomes, making them more susceptible to displacement. That at least some transcription factors can bind to their sites within nucleosomes is supported by in vivo studies of the PHO5 promoter that indicate that the Pho4 activator can bind its site prior to nucleosome disassembly (Adkins et al. 2004). While the nucleosome at its binding site does not have to be displaced before Pho4 can bind, Pho4 binding does appear to require acetylation of the nucleosome by the NuA4 complex (Nourani et al. 2004). Histone acetylation has been known to enhance transcription factor binding to nucleosomes in vitro for over a decade (Lee et al. 1993; Vettese-Dadey et al. 1996).

The genomic nucleosome mapping studies described above also support a role for transcription factors in generating nucleosome-free regions (Bernstein 2004; Raisner 2005). These studies demonstrated that the consensus binding site for the transcription factor Rap1 is often present in nucleosome-free promoters. Removal of this site from a test promoter allows nucleosome occupancy. Moreover, Rap1 plays a direct role in clearing nucleosomes from its binding site, thereby also assisting transcription factors that bind nearby (Yu and Morse 1999). In studies reported by Madhani and colleagues (Raisner et al. 2005), a 22-bp segment that contains both a dAdT tract and a binding site for the transcription factor Reb1 can also generate a nucleosome-free region flanked by H2A.Z-containing nucleosomes. Lastly, Rando and colleagues (Yuan et al. 2005) found that nucleosome-free gaps were enriched in sequences of poly dAdT. These poly dAdT tracts have been shown to act as upstream activating elements, apparently not by binding transcription factors but by excluding nucleosomes. Indeed, these elements can even stimulate transcription by bacteriophage T7 RNA polymerase in yeast cells, arguing for an indirect effect mediated through chromatin and not through the general transcription machinery (Chen et al. 1987).

Nucleosomes can be displaced from promoter DNA by promoter-binding transcription factors, as described above, in combination with ATP-dependent nucleosome remodeling complexes and histone chaperones (Steger and Workman 1996). It has been known for many years that the binding of multiple transcription factors to nucleosomes occurs in a "cooperative" manner and results in destabilization of the underlying nucleosome (Taylor et al. 1991; Workman and Kingston 1992; Juan et al. 1993; Morse 1993; Owen-Hughes and Workman 1996; Avolio-Hunter et al. 2001). In addition, nucleosome remodeling complexes of the SWI/SNF family (e.g., SWI/ SNF and RSC) have been shown to function in displacing histone octamers from one piece of DNA onto another (Lorch et al. 1999), through a mechanism that appears to involve forcing DNA bulges into the nucleosome (for review, see Flaus and Owen-Hughes 2004; Cairns 2005). This activity also facilitates exchange of histone H2A/ H2B dimers within nucleosomes (Bruno et al. 2003). Together, the binding of multiple transcription factors and 
the action of SWI/SNF are very potent at displacing histone octamers, and are able to generate targeted nucleosome-free regions in nucleosome arrays in purified systems (Owen-Hughes and Workman 1996).

The ability of DNA-binding transcription factors and nucleosome remodeling complexes to displace histone octamers is greatly facilitated by the presence of a histone sink. This sink can be in the form of naked DNA or histone chaperone proteins, each of which appears to induce histone displacement by a different mechanism. Displacement onto naked DNA appears to involve transfer of an intact histone octamers, whereas displacement onto chaperones occurs through disassembly of octamers into $\mathrm{H} 2 \mathrm{~A} / \mathrm{H} 2 \mathrm{~B}$ dimers and $\mathrm{H} 3 / \mathrm{H} 4$ tetramers (Walter et al. 1995). Indeed, nucleosome displacement in the presence of the histone chaperone Nap1 (nucleosome assembly protein 1) by the RSC (remodels the structure of chromatin) nucleosome remodeling complex occurs through a stepwise disassembly process (Lorch et al. 2006). Histone chaperones, also known as nucleosome assembly proteins, bind histones and facilitate their assembly into nucleosomes (for review, see Akey and Luger 2003). Presumably their role in nucleosome disassembly is simply a reverse of this process. While some histone chaperones/nucleosome assembly proteins (e.g., Nucleoplasmin, NAP-1) were discovered through their biochemical activity in assembling nucleosomes in vitro (Laskey et al. 1978; Ishimi et al. 1983), others have been identified in genetic screens as regulators of gene expression. Nucleosome assembly factors such as ASF1 (anti-silencing function 1), CAF1 (chromatin assembly factor 1), and HIR (histone regulatory) are required for gene silencing in yeast, presumably due to their role in nucleosome assembly (Sherwood et al. 1993; Kaufman et al. 1998; Sharp et al. 2001; Sutton et al. 2001; Lee et al. 2004). However, these factors have also been implicated in transcriptional activation in vivo and in vitro (Dimova et al. 1999; Adkins et al. 2004; Swaminathan et al. 2005; Zabaronick and Tyler 2005; Korber et al. 2006), consistent with a role in nucleosome disassembly.

\section{Role of histone modifications and variants in nucleosome displacement}

Histone modification and histone variants may also contribute to nucleosome displacement at promoters during gene activation (Fig. 1B). The observation that histones are first acetylated and then lost from the PHO5 promoter upon induction suggests that modification of histones by acetylation may play a role in nucleosome loss (Reinke and Horz 2003). The fact that the SWI/SNF complex binds to acetylated histones and that histone loss is dependent on SWI/SNF (Steger and Workman 1996; Hassan et al. 2001, 2002; Reinke and Horz 2003) suggest a direct connection between histone acetylation and nucleosome displacement. Promoter nucleosomes are also transiently acetylated at the HSP82 gene before their eviction following heat shock (Zhao et al. 2005). Lastly, Ito et al. (2000) have reported that histone acetylation by $\mathrm{P} 300$ facilitates the displacement of $\mathrm{H} 2 \mathrm{~A} / \mathrm{H} 2 \mathrm{~B}$ dimers onto the histone chaperone NAP-1 in an in vitro system that utilizes the ACF (ATP-utilizing chromatin assembly and remodeling factor) chromatin remodeling complex. Thus, there is a strong association between histone acetylation and the subsequent loss of histones.

Like histones modified by acetylation, histone variants have also been associated with nucleosome displacement. Nucleosomes containing the histone variant H2A.Z flank the nucleosome-free regions of inactive yeast promoters, and are preferentially displaced during gene activation (Guillemette et al. 2005; Li et al. 2005; Raisner et al. 2005; Zhang et al. 2005). This observation raises the question of whether H2A.Z plays a role in nucleosome displacement. Cairns and colleagues (Zhang et al. 2005) observed that H2A.Z is more easily released from chromatin than H2A, suggesting that H2A.Z nucleosomes may be less stable and therefore more easily displaced. This instability could be due, in part, to the fact that H2A.Z/H2B histone dimers are less stable than H2A/H2B histone dimers (Placek et al. 2005). H2A.Z has also been implicated in nucleosome positioning at the GAL1 promoter, which may play an important role in its activation (Guillemette et al. 2005). On the other hand, H2A.Z-containing nucleosomes show some resistance to modifications generally associated with transcription. H2A.Z-containing nucleosomes partially resist methylation by Dot 1 and Set 2 and acetylation by the NuA4 complex. These nucleosomes are less easily mobilized by nucleosome remodeling complexes ( $\mathrm{Li}$ et al. 2005). Together, these features have lead to the suggestion that, by resisting modifications associated with transcription, H2A.Z may help to establish a threshold that must be overcome for gene activation.

\section{Nucleosome displacement during transcription elongation}

A long-standing question in the chromatin field is: What happens to nucleosomes during transcription elongation (for review, see Adams and Workman 1993)? Early studies using prokaryotic RNA polymerases reported both that transcription elongation did and did not result in the displacement of nucleosomes, depending on the exact experiment (Brown 1984; Lorch et al. 1987, 1988). Detailed biochemical analysis suggested that nucleosomes could transfer from a position ahead of an elongating RNA polymerase to a position behind it. Such a mechanism appears to work in vitro for both bacteriophage polymerases and eukaryotic RNA polymerase III (Clark and Felsenfeld 1992; Studitsky et al. 1994, 1997; Bednar et al. 1999; Felsenfeld et al. 2000). Studies with RNA polymerase II, however, indicated that it is more difficult for polymerase II to pass a nucleosome and that doing so results in the loss of an H2A/H2B dimer (Kireeva et al. 2002; Studitsky et al. 2004). These and additional studies highlight the terrible conflict that occurs when RNA polymerase II encounters nucleosomes during transcription (Izban and Luse 1991; Chang and Luse 1997). The highly processive polymerase needs to elongate past sequences contained in nucleosomes that are blocking its 
path. Resolution of this conflict can actually damage the nucleosome, resulting in histone loss.

More recent studies have provided evidence that nucleosomes can be lost during transcription. First, genome-wide nucleosome mapping in yeast demonstrated the partial loss of nucleosomes over coding regions of the most heavily transcribed genes (Lee et al. 2004). Second, transcribed genes in larger eukaryotes accumulate the histone variant H3.3 (Ahmad and Henikoff 2002b). In contrast to nonvariant histone $3, \mathrm{H} 3.3$ is synthesized outside of $\mathrm{S}$ phase and is deposited onto DNA by a nucleosome assembly system distinct from that used for most nucleosome assembly during DNA replication (Ahmad and Henikoff 2002a; Tagami et al. 2004). These observations suggest that the H3-containing nucleosomes deposited during S phase are lost when the gene is transcribed and replaced with nucleosomes containing H3.3. Indeed, examination of several Drosophila genes revealed that nucleosomes containing either $\mathrm{H} 3$ or $\mathrm{H} 3.3$ were lost during activated transcription, and were selectively replaced with H3.3-containing nucleosomes (Wirbelauer et al. 2005). Interestingly, detailed analysis of the GAL10 locus in yeast, which has only the H3.3 form of $\mathrm{H} 3$, has shown that these histones are rapidly evicted and replaced during transcription elongation (Schwabish and Struhl 2004).

The results described above suggest the existence of mechanisms that partially or completely evict nucleosomal histones located in front of elongating RNA polymerase II, and mechanisms that coordinate the subsequent replacement of these histones (Fig. 1D). The importance of the latter step was revealed in studies of the functions of two elongation factors: Spt6 and Spt16. Biochemically, these two proteins act as histone chaperones. Spt6 colocalizes with elongating RNA polymerase (Hartzog et al. 1998; Kaplan et al. 2000). It interacts directly with histones (preferentially $\mathrm{H} 3$ ), and can function as a nucleosome assembly protein in vitro (Bortvin and Winston 1996). The Spt16 protein is associated with an HMG-like protein, SSRP1, in a complex termed FACT (facilitates chromatin transcription). FACT enhances transcription elongation through nucleosomes and interacts with $\mathrm{H} 2 \mathrm{~A} / \mathrm{H} 2 \mathrm{~B}$ dimers (Orphanides et al. 1999). Studies in vitro have shown that this effect of FACT occurs by removing an $\mathrm{H} 2 \mathrm{~A} / \mathrm{H} 2 \mathrm{~B}$ dimer, thereby destabilizing the nucleosome during polymerase passage (Belotserkovskaya et al. 2003).

Nucleosome reassembly behind passing RNA polymerase is critical to maintain the fidelity of transcription initiation. This striking finding came with the observation of short transcripts at particular yeast genes in Spt6 mutants (Kaplan et al. 2003). It turns out that nucleosome density is decreased in the ORFs of these genes in the absence of Spt6, and that transcription preinitiation complexes form fortuitously at cryptic TATA-like sequences in the ORF. Aberrant transcripts then initiate inside the ORFs from these preinitiation complexes. Similar effects were found in Spt16 mutants (Mason and Struhl 2003). These studies revealed a very fundamental role for nucleosomes in the fidelity of transcription.
Nucleosomes suppress cryptic TATA-like sequences in ORFs from serving as sites for transcription complex formation, thereby restricting initiation to promoters. In the absence of the histone chaperone/elongation factors Spt6 or Spt16, nucleosome density in the ORFs decreases during transcription elongation and cryptic TATA boxes are exposed.

It is important to note that all nucleosomes are not necessarily displaced and replaced by passing RNA polymerase, and that FACT and Spt6 do not necessarily function in exactly the same way. It has been proposed that FACT primarily displaces $\mathrm{H} 2 \mathrm{~A} / \mathrm{H} 2 \mathrm{~B}$ dimers from the nucleosome, whereas Spt6 may primarily act on H3/ H4 tetramers (Fig. 1D; Belotserkovskaya and Reinberg 2004). Moreover, while these proteins may transfer histones from positions ahead of elongating polymerases to positions behind them, the fact that replacement variants (i.e., H3.3) are incorporated into transcribed genes suggests that soluble histone pools are also used to rebuild nucleosomes behind polymerases. Thus, some of the original histones are lost and replaced during transcription. It is likely that the loss and replacement of $\mathrm{H} 2 \mathrm{~A} / \mathrm{H} 2 \mathrm{~B}$ dimers is greater than that of $\mathrm{H} 3 / \mathrm{H} 4$ tetramers. In principle, $\mathrm{H} 2 \mathrm{~A} / \mathrm{H} 2 \mathrm{~B}$ dimers would have to be removed before $\mathrm{H} 3 / \mathrm{H} 4$ tetramers because $\mathrm{H} 2 \mathrm{~A} /$ $\mathrm{H} 2 \mathrm{~B}$ dimers are outside of the $\mathrm{H} 3 / \mathrm{H} 4$ tetramers in the nucleosome. Thus, H2A/H2B may displace more often than $\mathrm{H} 3 / \mathrm{H} 4$. This is consistent with the pioneering studies of Jackson and Chalkley (1985) that illustrated that the timing and location of $\mathrm{H} 2 \mathrm{~A} / \mathrm{H} 2 \mathrm{~B}$ deposition into chromatin is somewhat different than $\mathrm{H} 3 / \mathrm{H} 4$ deposition and was more evident outside of $\mathrm{S}$ phase. These early studies may have reflected a more frequent replacement of $\mathrm{H} 2 \mathrm{~A} / \mathrm{H} 2 \mathrm{~B}$ than $\mathrm{H} 3 / \mathrm{H} 4$ in transcribed chromatin. More recently, photobleaching studies have demonstrated that $\mathrm{H} 2 \mathrm{~A} / \mathrm{H} 2 \mathrm{~B}$ dimers are more dynamic in euchromatin than H3/H4 tetramers (Kimura and Cook 2001).

\section{RNA polymerase signaling for maintenance of the repressive chromatin structure of transcribed regions}

Transcription elongation through chromatin results in modification of histones in the transcribed regions. This includes histone acetylation, $\mathrm{H} 3$ methylation, and $\mathrm{H} 2 \mathrm{~B}$ ubiquitylation. Moreover, enzymes carrying out these modifications have been found to travel with elongating RNA polymerase (Wittschieben et al. 1999; Krogan et al. 2003; Li et al. 2003; Schaft et al. 2003; Xiao et al. 2003, 2005). Histone acetylation may facilitate the disassembly of nucleosomes ahead of polymerase and/or their reassembly behind the polymerase (Svejstrup 2003). Indeed, genes that require the Gcn5 and Elp3 histone acetyltransferases for expression appear to be less susceptible to nucleosome loss during transcription (Somesh et al. 2005).

In principle, the consequences of cotranscriptional histone acetylation should include the accumulation of acetylated nucleosomes within transcribed regions. However, for reasons described below this is deleterious to the accuracy of initiation. Thus, elongating RNA polymerases signal for subsequent histone deacetylation. 
The elongating form of RNA polymerase II is phosphorylated at Ser2 on the C-terminal domain (CTD) repeats, which recruits the Set2 histone methyltransferase to the CTD. Set2 methylates H3 Lys 36 through the body of a gene as it is transcribed (Krogan et al. 2003; Li et al. 2003; Schaft et al. 2003; Xiao et al. 2003). Methylation of H3 $\mathrm{K} 36$ by Set 2 can repress basal transcription of the GAL4 gene (Landry et al. 2003) and generates a genetic requirement for positive-acting elongation factors (Keogh et al. 2005). Mutations in Set 2 or H3K36 result in an increased occupancy of RNA polymerase II in the coding region of the SCC2 gene (Kizer et al. 2005). These data indicate that cotranscriptional methylation of H3K36 by RNA polymerase II-associated Set2 is actually repressive for transcription.

The function of H3 methyl K36 in transcription is linked to histone deacetylation in transcribed regions. H3 methyl K36 represses transcription by recruiting a recently discovered Rpd3 histone deacetylase complex termed Rpd3S (Carrozza et al. 2005b; Keogh et al. 2005). Rpd3S shares three subunits with the larger Rpd3L complex, which serves to deacetylate and repress promoters (Carrozza et al. 2005a) but also contains two proteins not found in the large complex. One of these proteins, Eaf3, targets Rpd3S to H3 methyl K36 through a chromodomain (a methyl lysine-binding domain) found in it (Carrozza et al. 2005b; Keogh et al. 2005). Rpd3S recruited by H3 methyl K36 then removes transcription elongationinduced histone acetylation. Thus, the picture that emerges is that elongating RNA polymerase II carries with it histone acetyltransferase activities to facilitate passage through nucleosome (and perhaps reassembling nucleosomes behind it), and a methyltransferase to signal for subsequent histone deacetylation by Rpd3S (Carrozza et al. 2005b; Keogh et al. 2005). This signaling pathway (elongating polymerase II, phosphorylated CTD, Set2, H3 methyl K36, Rpd3S, histone deacetylation) allows the temporal separation of acetylation events during the passage of polymerase and subsequent histone deacetylation in the ORF. Thus, histone H3 methylation by Set 2 serves as a mark to subsequently deacetylate histone transcribed regions.

What might be the purpose of deacetylating histones within ORFs following transcription, especially if a gene is likely to be transcribed again? Mutations in any component in this signaling pathway from elongating RNA polymerase II to Rpd3S result in two changes within ORFs of several yeast genes. The first is increased acetylation of nucleosomes within the body of the gene, and the second is the appearance of transcripts initiating from cryptic TATA-like sequences within the ORF (Reid et al. 2004; Carrozza et al. 2005b; Joshi and Struhl 2005; Keogh et al. 2005). This occurs from many of the same sites from which cryptic transcripts initiate in Spt6 mutants described above (Kaplan et al. 2003; Carrozza et al. 2005b). Thus, the suppression of transcription from cryptic TATA-like sequences in transcribed regions requires both the restoration of nucleosomes behind elongating RNA polymerase II, and their deacetylation to generate a repressive chromatin environment.
There are a few unresolved mysteries regarding the Set2/Rpd3S signaling pathway. First, Eaf3 was originally identified as a component of the NuA4 promoter-targeted histone acetyltransferase complex (Eisen et al. 2001). Deletion of EAF3 leads to increased acetylation in ORFs, due to disruption of Rpd3S, and decreased acetylation at promoters, presumably due to disruption of NuA4 (Reid et al. 2004). It is unclear why NuA4 is apparently not also recruited to ORFs by Eaf3. Second, the lifespan of H3 methyl K36 resulting from Set2 methylation in ORFs is unknown. Does it continue to function through multiple rounds of transcription, perhaps eventually diluted away by nucleosome loss and replacement? Alternatively, it might be targeted for removal by JmjC domain-containing histone H3K36 demethylase (Tsukada et al. 2006). Finally, at very highly transcribed genes where nucleosome replacement apparently cannot keep up and partial nucleosome depletion in the ORF occurs (Lee et al. 2004), what prevents cryptic transcription initiation? One possibility is that high levels of accurate transcription prevent transcription complex formation at cryptic TATA-like sequences in the ORF. This type of mechanism has been described by Winston and colleagues (Martens et al. 2005) in studies showing that transcription initiating in an intergenic region transcribes through the yeast SER3 promoter, repressing its activity.

In summary, nucleosome displacement appears to be a widespread event in the process of transcription. A combination of transcription factor binding, histone acetylation, nucleosome remodeling complexes, and perhaps the histone variant $\mathrm{H} 2 \mathrm{AZ}$ target promoter nucleosomes for displacement upon gene induction to clear space for assembling the transcription machinery. In addition, nucleosomes are displaced during transcription elongation, where it is necessary to restore them to block TATA-like sequences in the transcribed region to prevent cryptic sites of initiation. Given the prevalence of nucleosome displacement in transcription, it seems likely that they will prove equally dynamic during other processes acting on the genome.

\section{Acknowledgments}

I thank Susan Abmayr and the reviewers of the manuscript for many helpful suggestions. Work in my laboratory is supported by NIGMS grant R37 GM047867 and the Stowers Institute for Medical Research.

\section{References}

Adams, C.C. and Workman, J.L. 1993. Nucleosome displacement in transcription. Cell 72: 305-308.

Adkins, M.W., Howar, S.R., and Tyler, J.K. 2004. Chromatin disassembly mediated by the histone chaperone Asf 1 is essential for transcriptional activation of the yeast PHO5 and PHO8 genes. Mol. Cell 14: 657-666.

Ahmad, K. and Henikoff, S. 2002a. Histone H3 variants specify modes of chromatin assembly. Proc. Natl. Acad. Sci. (Suppl. 4) 99: $16477-16484$.

. 2002b. The histone variant H3.3 marks active chromatin 
by replication-independent nucleosome assembly. Mol. Cell 9: 1191-1200.

Akey, C.W. and Luger, K. 2003. Histone chaperones and nucleosome assembly. Curr. Opin. Struct. Biol. 13: 6-14.

Angelov, D., Charra, M., Seve, M., Cote, J., Khochbin, S., and Dimitrov, S. 2000. Differential remodeling of the HIV-1 nucleosome upon transcription activators and SWI/SNF complex binding. J. Mol. Biol. 302: 315-326.

Avolio-Hunter, T.M., Lewis, P.N., and Frappier, L. 2001. Epstein-Barr nuclear antigen 1 binds and destabilizes nucleosomes at the viral origin of latent DNA replication. Nucleic Acids Res. 29: 3520-3528.

Babiarz, J.E., Halley, J.E., and Rine, J. 2006. Telomeric heterochromatin boundaries require NuA4-dependent acetylation of histone variant H2A.Z in Saccharomyces cerevisiae. Genes \& Dev. 20: 700-710.

Barton, M.C. and Crowe, A.J. 2001. Chromatin alteration, transcription and replication: What's the opening line to the story? Oncogene 20: 3094-3099.

Bednar, J., Studitsky, V.M., Grigoryev, S.A., Felsenfeld, G., and Woodcock, C.L. 1999. The nature of the nucleosomal barrier to transcription: Direct observation of paused intermediates by electron cryomicroscopy. Mol. Cell 4: 377-386.

Belotserkovskaya, R. and Reinberg, D. 2004. Facts about FACT and transcript elongation through chromatin. Curr. Opin. Genet. Dev. 14: 139-146.

Belotserkovskaya, R., Oh, S., Bondarenko, V.A., Orphanides, G., Studitsky, V.M., and Reinberg, D. 2003. FACT facilitates transcription-dependent nucleosome alteration. Science 301: 1090-1093.

Bernstein, B.E., Liu, C.L., Humphrey, E.L., Perlstein, E.O., and Schreiber, S.L. 2004. Global nucleosome occupancy in yeast. Genome Biol. 5: R62.

Boeger, H., Griesenbeck, J., Strattan, J.S., and Kornberg, R.D. 2003. Nucleosomes unfold completely at a transcriptionally active promoter. Mol. Cell 11: 1587-1598.

.2004. Removal of promoter nucleosomes by disassembly rather than sliding in vivo. Mol. Cell 14: 667-673.

Bortvin, A. and Winston, F. 1996. Evidence that Spt6p controls chromatin structure by a direct interaction with histones. Science 272: 1473-1476.

Bresnick, E.H., Bustin, M., Marsaud, V., Richard-Foy, H., and Hager, G.L. 1992. The transcriptionally-active MMTV promoter is depleted of histone H1. Nucleic Acids Res. 20: 273278.

Brown, D.D. 1984. The role of stable complexes that repress and activate eucaryotic genes. Cell 37: 359-365.

Brown, C.E., Howe, L., Sousa, K., Alley, S.C., Carrozza, M.J., Tan, S., and Workman, J.L. 2001. Recruitment of HAT complexes by direct activator interactions with the ATM-related Tral subunit. Science 292: 2333-2337.

Bruno, M., Flaus, A., Stockdale, C., Rencurel, C., Ferreira, H., and Owen-Hughes, T. 2003. Histone H2A/H2B dimer exchange by ATP-dependent chromatin remodeling activities. Mol. Cell 12: 1599-1606.

Cairns, B.R. 2005. Chromatin remodeling complexes: Strength in diversity, precision through specialization. Curr. Opin. Genet. Dev. 15: 185-190.

Carrozza, M.J., Florens, L., Swanson, S.K., Shia, W.J., Anderson, S., Yates, J., Washburn, M.P., and Workman, J.L. 2005a. Stable incorporation of sequence specific repressors Ash1 and Ume6 into the Rpd3L complex. Biochim. Biophys. Acta 1731: $77-87$.

Carrozza, M.J., Li, B., Florens, L., Suganuma, T., Swanson, S.K., Lee, K.K., Shia, W.J., Anderson, S., Yates, J., Washburn, M.P., et al. 2005b. Histone $\mathrm{H} 3$ methylation by Set2 directs deacetylation of coding regions by Rpd3S to suppress spurious intragenic transcription. Cell 123: 581-592.

Chang, C.H. and Luse, D.S. 1997. The H3/H4 tetramer blocks transcript elongation by RNA polymerase II in vitro. J. Biol. Chem. 272: 23427-23434.

Chen, W., Tabor, S., and Struhl, K. 1987. Distinguishing between mechanisms of eukaryotic transcriptional activation with bacteriophage T7 RNA polymerase. Cell 50: 1047-1055.

Chen, X., Wang, J., Woltring, D., Gerondakis, S., and Shannon, M.F. 2005. Histone dynamics on the interleukin-2 gene in response to T-cell activation. Mol. Cell. Biol. 25: 3209-3219.

Clark, D.J. and Felsenfeld, G. 1992. A nucleosome core is transferred out of the path of a transcribing polymerase. Cell 71: $11-22$.

Dimova, D., Nackerdien, Z., Furgeson, S., Eguchi, S., and Osley, M.A. 1999. A role for transcriptional repressors in targeting the yeast Swi/Snf complex. Mol. Cell 4: 75-83.

Eisen, A., Utley, R.T., Nourani, A., Allard, S., Schmidt, P., Lane, W.S., Lucchesi, J.C., and Cote, J. 2001. The yeast NuA4 and Drosophila MSL complexes contain homologous subunits important for transcription regulation. J. Biol. Chem. 276: 3484-3491.

Elgin, S.C. 1981. DNAase I-hypersensitive sites of chromatin. Cell 27: 413-415.

Ercan, S. and Simpson, R.T. 2004. Global chromatin structure of 45,000 base pairs of chromosome III in a- and $\alpha$-cell yeast and during mating-type switching. Mol. Cell. Biol. 24: 1002610035.

Ercan, S., Carrozza, M.J., and Workman, J.L. 2004. Global nucleosome distribution and the regulation of transcription in yeast. Genome Biol. 5: 243.

Felsenfeld, G., Clark, D., and Studitsky, V. 2000. Transcription through nucleosomes. Biophys. Chem. 86: 231-237.

Flaus, A. and Owen-Hughes, T. 2004. Mechanisms for ATPdependent chromatin remodelling: Farewell to the tuna-can octamer? Curr. Opin. Genet. Dev. 14: 165-173.

Gross, D.S. and Garrard, W.T. 1988. Nuclease hypersensitive sites in chromatin. Annu. Rev. Biochem. 57: 159-197.

Guillemette, B., Bataille, A.R., Gevry, N., Adam, M., Blanchette, M., Robert, F., and Gaudreau, L. 2005. Variant histone H2A.Z is globally localized to the promoters of inactive yeast genes and regulates nucleosome positioning. PLOS Biol. 3: e384.

Hartzog, G.A., Wada, T., Handa, H., and Winston, F. 1998. Evidence that Spt4, Spt5, and Spt6 control transcription elongation by RNA polymerase II in Saccharomyces cerevisiae. Genes \& Dev. 12: 357-369.

Hassan, A.H., Neely, K.E., and Workman, J.L. 2001. Histone acetyltransferase complexes stabilize swi/snf binding to promoter nucleosomes. Cell 104: 817-827.

Hassan, A.H., Prochasson, P., Neely, K.E., Galasinski, S.C., Chandy, M., Carrozza, M.J., and Workman, J.L. 2002. Function and selectivity of bromodomains in anchoring chromatin-modifying complexes to promoter nucleosomes. Cell 111: 369-379.

Ishimi, Y., Yasuda, H., Hirosumi, J., Hanaoka, F., and Yamada, M. 1983. A protein which facilitates assembly of nucleosome-like structures in vitro in mammalian cells. J. Biochem. 94: 735-744.

Ito, T., Ikehara, T., Nakagawa, T., Kraus, W.L., and Muramatsu, M. 2000. p300-mediated acetylation facilitates the transfer of histone $\mathrm{H} 2 \mathrm{~A}-\mathrm{H} 2 \mathrm{~B}$ dimers from nucleosomes to a histone chaperone. Genes \& Dev. 14: 1899-1907.

Izban, M.G. and Luse, D.S. 1991. Transcription on nucleosomal templates by RNA polymerase II in vitro: Inhibition of elon- 
gation with enhancement of sequence-specific pausing. Genes \& Dev. 5: 683-696.

Jackson, V. and Chalkley, R. 1985. Histone synthesis and deposition in the G1 and S phases of hepatoma tissue culture cells. Biochemistry 24: 6921-6930.

Joshi, A.A. and Struhl, K. 2005. Eaf3 chromodomain interaction with methylated H3-K36 links histone deacetylation to Pol II elongation. Mol. Cell 20: 971-978.

Juan, L.J., Walter, P.P., Taylor, I.C., Kingston, R.E., and Workman, J.L. 1993. Nucleosome cores and histone $\mathrm{H} 1$ in the binding of GAL4 derivatives and the reactivation of transcription from nucleosome templates in vitro. Cold Spring Harb. Symp. Quant. Biol. 58: 213-223.

Kaplan, C.D., Morris, J.R., Wu, C., and Winston, F. 2000. Spt5 and spt 6 are associated with active transcription and have characteristics of general elongation factors in D. melanogaster. Genes \& Dev. 14: 2623-2634.

Kaplan, C.D., Laprade, L., and Winston, F. 2003. Transcription elongation factors repress transcription initiation from cryptic sites. Science 301: 1096-1099.

Kaufman, P.D., Cohen, J.L., and Osley, M.A. 1998. Hir proteins are required for position-dependent gene silencing in Saccharomyces cerevisiae in the absence of chromatin assembly factor I. Mol. Cell. Biol. 18: 4793-4806.

Keogh, M.C., Kurdistani, S.K., Morris, S.A., Ahn, S.H., Podolny, V., Collins, S.R., Schuldiner, M., Chin, K., Punna, T., Thompson, N.J., et al. 2005. Cotranscriptional set2 methylation of histone $\mathrm{H} 3$ lysine 36 recruits a repressive $\mathrm{Rpd} 3 \mathrm{com}$ plex. Cell 123: 593-605.

Keogh, M.C., Mennella, T.A., Sawa, C., Berthelet, S., Krogan, N.J., Wolek, A., Podolny, V., Carpenter, L.R., Greenblatt, J.F., Baetz, K., et al. 2006. The Saccharomyces cerevisiae histone H2A variant Htzl is acetylated by NuA4. Genes \& Dev. 20: 660-665.

Kimura, H. and Cook, P.R. 2001. Kinetics of core histones in living human cells: Little exchange of $\mathrm{H} 3$ and $\mathrm{H} 4$ and some rapid exchange of H2B. J. Cell Biol. 153: 1341-1353.

Kireeva, M.L., Walter, W., Tchernajenko, V., Bondarenko, V., Kashlev, M., and Studitsky, V.M. 2002. Nucleosome remodeling induced by RNA polymerase II: Loss of the H2A/H2B dimer during transcription. Mol. Cell 9: 541-552.

Kizer, K.O., Phatnani, H.P., Shibata, Y., Hall, H., Greenleaf, A.L., and Strahl, B.D. 2005. A novel domain in Set2 mediates RNA polymerase II interaction and couples histone H3 K36 methylation with transcript elongation. Mol. Cell. Biol. 25: 3305-3316.

Korber, P., Luckenbach, T., Blaschke, D., and Horz, W. 2004. Evidence for histone eviction in trans upon induction of the yeast PHO5 promoter. Mol. Cell. Biol. 24: 10965-10974.

Korber, P., Barbaric, S., Luckenbach, T., Schmid, A., Schermer, U.J., Blaschke, D., and Horz, W. 2006. The histone chaperone Asf1 increases the rate of histone eviction at the yeast PHO5 and PHO8 promoters. J. Biol. Chem. 281: 5539-5545.

Kornberg, R.D. and Lorch, Y. 1991. Irresistible force meets immovable object: Transcription and the nucleosome. Cell 67: 833-836.

Krogan, N.J., Kim, M., Tong, A., Golshani, A., Cagney, G., Canadien, V., Richards, D.P., Beattie, B.K., Emili, A., Boone, C., et al. 2003. Methylation of histone H3 by Set2 in Saccharomyces cerevisiae is linked to transcriptional elongation by RNA polymerase II. Mol. Cell. Biol. 23: 4207-4218.

Landry, J., Sutton, A., Hesman, T., Min, J., Xu, R.M., Johnston, M., and Sternglanz, R. 2003. Set2-catalyzed methylation of histone H3 represses basal expression of GAL4 in Saccharomyces cerevisiae. Mol. Cell. Biol. 23: 5972-5978.

Laskey, R.A., Honda, B.M., Mills, A.D., and Finch, J.T. 1978.
Nucleosomes are assembled by an acidic protein which binds histones and transfers them to DNA. Nature 275: 416-420.

Lee, D.Y., Hayes, J.J., Pruss, D., and Wolffe, A.P. 1993. A positive role for histone acetylation in transcription factor access to nucleosomal DNA. Cell 72: 73-84.

Lee, C.K., Shibata, Y., Rao, B., Strahl, B.D., and Lieb, J.D. 2004. Evidence for nucleosome depletion at active regulatory regions genome-wide. Nat. Genet. 36: 900-905.

Li, B., Howe, L., Anderson, S., Yates III, J.R., and Workman, J.L. 2003. The Set 2 histone methyltransferase functions through the phosphorylated carboxyl-terminal domain of RNA polymerase II. J. Biol. Chem. 278: 8897-8903.

Li, B., Pattenden, S.G., Lee, D., Gutierrez, J., Chen, J., Seidel, C., Gerton, J., and Workman, J.L. 2005. Preferential occupancy of histone variant $\mathrm{H} 2 \mathrm{AZ}$ at inactive promoters influences local histone modifications and chromatin remodeling. Proc. Natl. Acad. Sci. 102: 18385-18390.

Liu, C.L., Kaplan, T., Kim, M., Buratowski, S., Schreiber, S.L., Friedman, N., and Rando, O.J. 2005. Single-nucleosome mapping of histone modifications in S. cerevisiae. PLoS Biol. 3: e328.

Lorch, Y., LaPointe, J.W., and Kornberg, R.D. 1987. Nucleosomes inhibit the initiation of transcription but allow chain elongation with the displacement of histones. Cell 49: 203210.

-1988. On the displacement of histones from DNA by transcription. Cell 55: 743-744.

Lorch, Y., Zhang, M., and Kornberg, R.D. 1999. Histone octamer transfer by a chromatin-remodeling complex. Cell 96: 389392.

Lorch, Y., Maier-Davis, B., and Kornberg, R.D. 2006. Chromatin remodeling by nucleosome disassembly in vitro. Proc. Natl. Acad. Sci. 103: 3090-3093.

Martens, J.A., Wu, P.Y., and Winston, F. 2005. Regulation of an intergenic transcript controls adjacent gene transcription in Saccharomyces cerevisiae. Genes \& Dev. 19: 2695-2704.

Mason, P.B. and Struhl, K. 2003. The FACT complex travels with elongating RNA polymerase II and is important for the fidelity of transcriptional initiation in vivo. Mol. Cell. Biol. 23: $8323-8333$.

McGhee, J.D., Wood, W.I., Dolan, M., Engel, J.D., and Felsenfeld, G. 1981. A 200 base pair region at the $5^{\prime}$ end of the chicken adult $\beta$-globin gene is accessible to nuclease digestion. Cell 27: 45-55.

Millar, C.B., Xu, F., Zhang, K., and Grunstein, M. 2006. Acetylation of $\mathrm{H} 2 \mathrm{AZ}$ Lys 14 is associated with genome-wide gene activity in yeast. Genes \& Dev. 20: 711-722.

Morse, R.H. 1993. Nucleosome disruption by transcription factor binding in yeast. Science 262: 1563-1566.

Nourani, A., Utley, R.T., Allard, S., and Cote, J. 2004. Recruitment of the NuA4 complex poises the PHO5 promoter for chromatin remodeling and activation. EMBO J. 23: 25972607.

Orphanides, G., Wu, W.H., Lane, W.S., Hampsey, M., and Reinberg, D. 1999. The chromatin-specific transcription elongation factor FACT comprises human SPT16 and SSRP1 proteins. Nature 400: 284-288.

Owen-Hughes, T. and Workman, J.L. 1996. Remodeling the chromatin structure of a nucleosome array by transcription factor-targeted trans-displacement of histones. EMBO J. 15: 4702-4712.

Placek, B.J., Harrison, L.N., Villers, B.M., and Gloss, L.M. 2005. The H2A.Z/H2B dimer is unstable compared to the dimer containing the major H2A isoform. Protein Sci. 14: 514-522.

Raisner, R.M., Hartley, P.D., Meneghini, M.D., Bao, M.Z., Liu, C.L., Schreiber, S.L., Rando, O.J., and Madhani, H.D. 2005. 
Histone variant H2A.Z marks the $5^{\prime}$ ends of both active and inactive genes in euchromatin. Cell 123: 233-248.

Reid, J.L., Moqtaderi, Z., and Struhl, K. 2004. Eaf3 regulates the global pattern of histone acetylation in Saccharomyces cerevisiae. Mol. Cell. Biol. 24: 757-764.

Reinke, H. and Horz, W. 2003. Histones are first hyperacetylated and then lose contact with the activated PHO5 promoter. Mol. Cell 11: 1599-1607.

Santisteban, M.S., Kalashnikova, T., and Smith, M.M. 2000. Histone $\mathrm{H} 2 \mathrm{~A} . \mathrm{Z}$ regulats transcription and is partially redundant with nucleosome remodeling complexes. Cell 103: 411-422.

Schaft, D., Roguev, A., Kotovic, K.M., Shevchenko, A., Sarov, M., Neugebauer, K.M., and Stewart, A.F. 2003. The histone 3 lysine 36 methyltransferase, SET2, is involved in transcriptional elongation. Nucleic Acids Res. 31: 2475-2482.

Schwabish, M.A. and Struhl, K. 2004. Evidence for eviction and rapid deposition of histones upon transcriptional elongation by RNA polymerase II. Mol. Cell. Biol. 24: 10111-10117.

Sharp, J.A., Fouts, E.T., Krawitz, D.C., and Kaufman, P.D. 2001. Yeast histone deposition protein Asflp requires Hir proteins and PCNA for heterochromatic silencing. Curr. Biol. 11: 463-473.

Sherwood, P.W., Tsang, S.V., and Osley, M.A. 1993. Characterization of HIR1 and HIR2, two genes required for regulation of histone gene transcription in Saccharomyces cerevisiae. Mol. Cell. Biol. 13: 28-38.

Somesh, B.P., Reid, J., Liu, W.F., Sogaard, T.M., Erdjument-Bromage, H., Tempst, P., and Svejstrup, J.Q. 2005. Multiple mechanisms confining RNA polymerase II ubiquitylation to polymerases undergoing transcriptional arrest. Cell 121: 913-923.

Steger, D.J. and Workman, J.L. 1996. Remodeling chromatin structures for transcription: What happens to the histones? Bioessays 18: 875-884.

.1997. Stable co-occupancy of transcription factors and histones at the HIV-1 enhancer. EMBO J. 16: 2463-2472.

Studitsky, V.M., Clark, D.J., and Felsenfeld, G. 1994. A histone octamer can step around a transcribing polymerase without leaving the template. Cell 76: 371-382.

Studitsky, V.M., Kassavetis, G.A., Geiduschek, E.P., and Felsenfeld, G. 1997. Mechanism of transcription through the nucleosome by eukaryotic RNA polymerase. Science 278: 1960-1963.

Studitsky, V.M., Walter, W., Kireeva, M., Kashlev, M., and Felsenfeld, G. 2004. Chromatin remodeling by RNA polymerases. Trends Biochem. Sci. 29: 127-135.

Sutton, A., Bucaria, J., Osley, M.A., and Sternglanz, R. 2001. Yeast ASF1 protein is required for cell cycle regulation of histone gene transcription. Genetics 158: 587-596.

Svaren, J. and Horz, W. 1997. Transcription factors vs. nucleosomes: Regulation of the PHO5 promoter in yeast. Trends Biochem. Sci. 22: 93-97.

Svejstrup, J.Q. 2003. Transcription. Histones face the FACT. Science 301: 1053-1055.

Swaminathan, V., Kishore, A.H., Febitha, K.K., and Kundu, T.K. 2005. Human histone chaperone nucleophosmin enhances acetylation-dependent chromatin transcription. Mol. Cell. Biol. 25: 7534-7545.

Tagami, H., Ray-Gallet, D., Almouzni, G., and Nakatani, Y. 2004. Histone H3.1 and H3.3 complexes mediate nucleosome assembly pathways dependent or independent of DNA synthesis. Cell 116: 51-61.

Taylor, I.C., Workman, J.L., Schuetz, T.J., and Kingston, R.E. 1991. Facilitated binding of GAL4 and heat shock factor to nucleosomal templates: Differential function of DNA-bind- ing domains. Genes \& Dev. 5: 1285-1298.

Truss, M., Bartsch, J., Schelbert, A., Hache, R.J., and Beato, M. 1995. Hormone induces binding of receptors and transcription factors to a rearranged nucleosome on the MMTV promoter in vivo. EMBO J. 14: 1737-1751.

Tsukada, Y., Fang, J., Erdjument-Bromage, H., Warren, M.E., Borchers, C.H., Tempst, P., and Zhang, Y. 2006. Histone demethylation by a family of JmjC domain-containing proteins. Nature 439: 811-816.

Utley, R.T., Ikeda, K., Grant, P.A., Cote, J., Steger, D.J., Eberharter, A., John, S., and Workman, J.L. 1998. Transcriptional activators direct histone acetyltransferase complexes to nucleosomes. Nature 394: 498-502.

Vettese-Dadey, M., Grant, P.A., Hebbes, T.R., Crane-Robinson, C., Allis, C.D., and Workman, J.L. 1996. Acetylation of histone $\mathrm{H} 4$ plays a primary role in enhancing transcription factor binding to nucleosomal DNA in vitro. EMBO J. 15: 2508-2518.

Vicent, G.P., Nacht, A.S., Smith, C.L., Peterson, C.L., Dimitrov, S., and Beato, M. 2004. DNA instructed displacement of histones $\mathrm{H} 2 \mathrm{~A}$ and $\mathrm{H} 2 \mathrm{~B}$ at an inducible promoter. Mol. Cell 16: 439-452.

Walter, P.P., Owen-Hughes, T.A., Cote, J., and Workman, J.L. 1995. Stimulation of transcription factor binding and histone displacement by nucleosome assembly protein 1 and nucleoplasmin requires disruption of the histone octamer. Mol. Cell. Biol. 15: 6178-6187.

Wirbelauer, C., Bell, O., and Schubeler, D. 2005. Variant histone H3.3 is deposited at sites of nucleosomal displacement throughout transcribed genes while active histone modifications show a promoter-proximal bias. Genes \& Dev. 19: 1761-1766.

Wittschieben, B.O., Otero, G., de Bizemont, T., Fellows, J., Erdjument-Bromage, H., Ohba, R., Li, Y., Allis, C.D., Tempst, P., and Svejstrup, J.Q. 1999. A novel histone acetyltransferase is an integral subunit of elongating RNA polymerase II holoenzyme. Mol. Cell 4: 123-128.

Workman, J.L. and Kingston, R.E. 1992. Nucleosome core displacement in vitro via a metastable transcription factornucleosome complex. Science 258: 1780-1784.

Xiao, T., Hall, H., Kizer, K.O., Shibata, Y., Hall, M.C., Borchers, C.H., and Strahl, B.D. 2003. Phosphorylation of RNA polymerase II CTD regulates H3 methylation in yeast. Genes \& Dev. 17: 654-663.

Xiao, T., Kao, C.F., Krogan, N.J., Sun, Z.W., Greenblatt, J.F., Osley, M.A., and Strahl, B.D. 2005. Histone H2B ubiquitylation is associated with elongating RNA polymerase II. Mol. Cell. Biol. 25: 637-651.

Yu, L. and Morse, R.H. 1999. Chromatin opening and transactivator potentiation by RAP1 in Saccharomyces cerevisiae. Mol. Cell. Biol. 19: 5279-5288.

Yuan, G.C., Liu, Y.J., Dion, M.F., Slack, M.D., Wu, L.F., Altschuler, S.J., and Rando, O.J. 2005. Genome-scale identification of nucleosome positions in S. cerevisiae. Science 309: 626-630.

Zabaronick, S.R. and Tyler, J.K. 2005. The histone chaperone anti-silencing function 1 is a global regulator of transcription independent of passage through S phase. Mol. Cell. Biol. 25: 652-660.

Zhang, H., Roberts, D.N., and Cairns, B.R. 2005. Genome-wide dynamics of Htz1, a histone H2A variant that poises repressed/basal promoters for activation through histone loss. Cell 123: 219-231.

Zhao, J., Herrera-Diaz, J., and Gross, D.S. 2005. Domain-wide displacement of histones by activated heat shock factor occurs independently of Swi/Snf and is not correlated with RNA polymerase II density. Mol. Cell. Biol. 25: 8985-8999. 


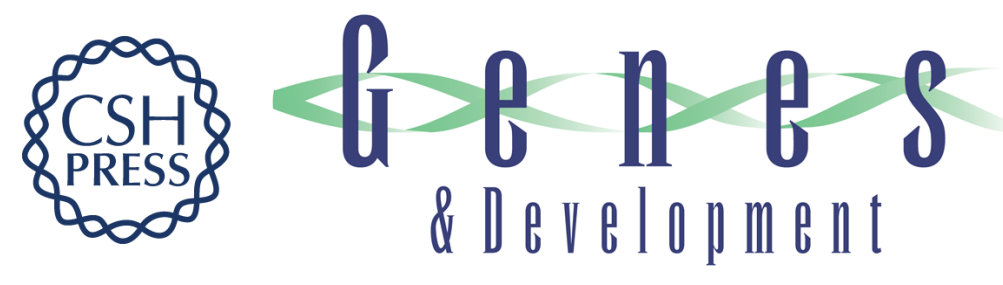

\section{Nucleosome displacement in transcription}

Jerry L. Workman

Genes Dev. 2006, 20:

Access the most recent version at doi:10.1101/gad.1435706

References This article cites 109 articles, 46 of which can be accessed free at: http://genesdev.cshlp.org/content/20/15/2009.full.html\#ref-list-1

License

Email Alerting Receive free email alerts when new articles cite this article - sign up in the box at the top Service right corner of the article or click here.

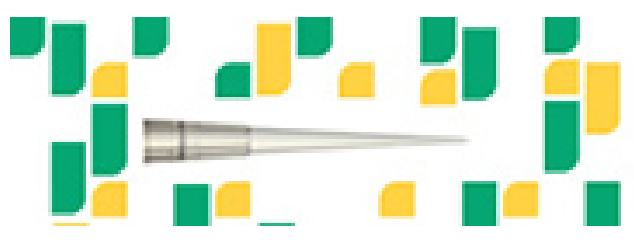

Focused on your science. 